\title{
Intra and interindividual variability in the kinetics of a poorly and highly metabolising solvent
}

\author{
J J G OPDAM \\ From the Coronel Laboratory, Faculty of Medicine, University of Amsterdam, 1105 AZ Amsterdam, The \\ Netherlands
}

ABSTRACT Human subjects were experimentally exposed three times simultaneously to tetrachloroethene (PER) and trichloroethene (TRI) under conditions of rest and exercise. In each subject the individual kinetics for both PER and TRI were determined three times by means of frequent sampling of alveolar air up to 70-500 and 20-310 hours respectively. For PER the following parameters were found: the weighted pulmonary clearance $\left(\overline{\mathrm{Cl}}_{\mathrm{pul}}\right)=0.27-0.64 \mathrm{l} / \mathrm{min}$, terminal half time $\left(\mathrm{t}_{\mathrm{t}(\mathrm{z})}\right)=54-250$ hours, mean residence time $(\mathrm{MRT})=35-155$ hours, and volume of distribution $\left(V_{d s s}\right)=1100-35701$. For TRI the apparent hepatic clearance $\left(C L_{h e p}\right)=0.5-1.71 / \mathrm{min}$, weighted $\mathrm{Cl}_{\text {pul }}=0.41-1.48 \mathrm{l} / \mathrm{min}, \mathrm{t}_{\mathrm{t}(\mathrm{z})}=13-55$ hours, $\mathrm{MRT}=2 \cdot 3-22$ hours, and the $\mathrm{V}_{\mathrm{dss}}=420-31001$. The intra and intersubject variation in the kinetics were reflected in the predictions of the individual time course of the solvent in the blood at repeated exposure up to five weeks (eight hours a day, five days a week). For PER the intrasubject variation in the predicted concentrations on the Monday mornings was within $5-15 \%$ whereas the intersubject variation was about twofold. For TRI the intrasubject variation in the predicted morning concentrations was substantial (two to threefold), whereas the intersubject variation was about 10 -fold. The intrasubject variation was probably caused mainly by the level of exercise during exposure. The $\mathrm{Cl}_{\text {hep }}$ was not greatly influenced by the level of exercise, whereas exercise during exposure increased the MRT. Exercise during exposure probably speeds up the process of distribution and, therefore, there is a lower concentration in the blood relative to the increased respiratory intake. As a consequence, despite the increased $\mathrm{Cl}_{\text {pul }}$ and the rather unchanged $\mathrm{Cl}_{\text {hep }}$, pulmonary and metabolic excretion will be delayed and the MRT increased. The MRT is more suited to predict the individual cumulation of both PER and TRI than the terminal $t_{\frac{1}{(}(\mathrm{z})}$.

In general, human exposure experiments are well suited for the assessment of the kinetics of drugs and solvents in an individual subject.

The analysis of concentration time is often interpreted by means of compartment models. The measured data are fitted to a sum of exponential terms and the number of the exponents is usually interpreted as the number of the compartments. The number of fitted exponents, however, depends on the accuracy and precision of the data and the duration of observation. This means that the distribution and the elimination half times are difficult to compare among different experiments from different investigators. Furthermore, the obtained time course of, for example, the solvent concentration in blood does not give one unique compartment model. It has been shown that

Accepted 19 December 1988 different models may be derived from the same time course and the redundancy of the use of these models in most kinetic problems has been shown.'

In recent years model independent approaches have been used more often. For example, the elimination half time $t_{t(2)}$ and the area (AUC) under the concentration time course may be calculated without the use of a compartment model. For the analysis of the entire concentration time course statistical moments have been introduced. ${ }^{23}$ Statistical moments are integrated approaches and, therefore, in principle they are independent of the fitted model consisting of a sum of exponentials or polynomials. The significance of statistical moments of concentration time courses as pharmacokinetic parameters has been discussed recently by several authors. ${ }^{2-7}$

The purpose of the present paper was to study the intra and intersubject variation in the kinetics of a highly and a poorly metabolised solvent by means of 
the elimination half time $\left(t_{t(z)}\right)$, the mean residence time (MRT), pulmonary clearance $\left(\mathrm{Cl}_{\text {pul }}\right)$, and the hepatic clearance $\left(\mathrm{Cl}_{\text {hep }}\right)$. Furthermore, the concentration time course of the solvent in blood was predicted on an individual basis during five weeks of repeated exposure. The predicted individual solvent concentrations in the blood are compared with the outcome of a physiological simulation model ${ }^{8}$ and of studies on biological monitoring of occupational exposure.

Men and women were exposed simultaneously to a vapour of poorly metabolising (inert) tetrachloroethene (PER) and of highly metabolising trichloroethene (TRI). Exposures were carried out at rest and at physical exercise as described in previous papers. ${ }^{9-11}$

\section{Methods}

\section{PROCEDURE}

In a first set of experiments four subjects (two men, two women) were exposed twice at rest to PER. A second set of experiments was carried out with six subjects (three men, three women); each subject was exposed three times simultaneously to PER and TRI at rest, $30 \mathrm{~W}$, and 65 Watt physical exercise. The duration of exposure was 29-62 minutes and the total observation periods lasted 70-500 hours for PER and 20-310 hours for TRI. Concentrations in inhaled air $\left(C_{1}\right)$ ranged from 0.11 to $0.43 \mu \mathrm{mol} / 1$ for PER and from 0.24 to $1.58 \mu \mathrm{mol} / 1$ for TRI. The exposure data have been presented in a previous paper. ${ }^{11}$ The conditions of exposure, the method of alveolar sampling, the sampling protocol, and the sampling errors have been described in detail elsewhere. ${ }^{911}$ The subjects were asked not to consume alcohol and not to partake in vigorous sporting activities during the first three postexposure days. After this the subjects followed their normal daily life style.

Table 1 gives the individual data on the subjects. They were aged 24-38; the percentage of fat according to the method of Durnin and Wormersley was 10 $26 \%$ and $25-31 \%$ for the men and women respec-

Table 1 Individual characteristics of subjects

\begin{tabular}{llllll}
\hline Subject & $\begin{array}{l}\text { Age } \\
(y)\end{array}$ & $\begin{array}{l}\text { Height } \\
(\mathrm{cm})\end{array}$ & $\begin{array}{l}\text { Weight } \\
(\mathrm{kg})\end{array}$ & $\begin{array}{l}\% \mathrm{fat}^{*} \\
(\%)\end{array}$ & $\begin{array}{l}\dot{V}_{\mathbf{g}}^{* \dagger} \\
(\mathrm{l} / \mathrm{min})\end{array}$ \\
\hline Im & 38 & 178 & 84 & 26 & $7 \cdot 5$ \\
2m & 30 & 188 & 74 & 16 & $6 \cdot 9$ \\
3m & 26 & 182 & 69 & 19 & $6 \cdot 9$ \\
4m & 25 & 186 & 73 & 10 & $7 \cdot 5$ \\
If & 28 & 165 & 60 & 31 & $5 \cdot 3$ \\
2f & 24 & 161 & 60 & 27 & $4 \cdot 5$ \\
3f & 28 & 162 & 61 & 31 & $6 \cdot 6$ \\
4f & 27 & 177 & $63 \cdot 5$ & 27 & $5 \cdot 5$ \\
5f & 27 & 165 & 60 & 25 & $5 \cdot 2$ \\
\hline
\end{tabular}

"Percentage fat of body weight. ${ }^{12}$

† Mean postexposure alveolar ventilation $\left(\mathrm{V}_{\mathrm{a}}^{*}\right)$ from two or three experiments. tively. ${ }^{12}$ The postexposure alveolar ventilation $(\dot{\overline{\mathrm{V}}} \overline{\overline{\mathrm{a}}} \overline{\mathrm{a}})$ has been determined according to the method given an earlier paper. ${ }^{10}$

In all subjects the individual kinetics of PER a d TRI were determined two or three times 9 experiments with exposure at rest, $30 \mathrm{~W}$, and $65 \mathrm{~W}$ exercise.

\section{PREDICTION OF THE CONCENTRATION TIME COURSES}

To estimate the individual time course of the solvent concentration in blood at repeated exposure the theory of system dynamics has been used in which the relation between the rate of input and the kinefic response is studied. This relation is a convolution integral in which a weighting function $g(t)$-that $\stackrel{s}{s}$, unit impulse response- - weights past values to give the present value of the response. When two of the thrige (rate of input, kinetic response, or unit impubse response) are known, the third may be calculated with a suitable method for convolution or decopvolution..$^{1314}$

The rate of input in inhalation experiments wais defined as the rate of functional intake (RFI), whioh equals the product of the inhaled concentration ( $\left.\mathbb{S}_{\text {S }}\right)$ and the functional alveolar ventilation $\left(\dot{\mathrm{V}}_{\mathrm{a}}\right){ }^{10}$ (Sy bols and abbreviations are given in appendix 1.)

The kinetic response equals the concentratiog $\overrightarrow{\dot{\phi}}$ mixed venous blood $\left(\mathrm{C}_{\text {ven }}\right)$ measured by means of the concentration $\left(\mathrm{C}_{\mathrm{alv}, \mathrm{eq}}\right)$ in alveolar air in equilib with $\mathrm{C}_{\text {ven. }}$.

The unit impulse response $\mathrm{g}(\mathrm{t})$ may be experime tally determined in inhalation experiments when boon the rate of input and the response are known. ${ }^{11}$ On tîne other hand, once the unit impulse response is known the kinetic response may be predicted at each chosen pattern of the respiratory input.

For each subject the time course of $\mathrm{C}_{\mathrm{alv}, \mathrm{eq}}\left(=\mathrm{C}_{\mathrm{ven}}\right.$ 苞$)$ was predicted at repeated exposures to PER and TRI during five weeks with a $5 \times 8$ hours workshit (appendix 2).

The concentration in the blood after an infinife duration of exposure (steady state) for a metabolising solvent may be estimated on an individual base when the hepatic and pulmonary clearance are known (appendix 3).

Predictions based on the individual experimental determined unit impulse responses were compared with predictions based on those of a standard person. The predictions for a standard person were derived from a theoretical simulation model based on $\mathrm{Ca}^{-}$ number of assumptions on local blood flows, tissule volumes, and partition coefficients. ${ }^{8}$ The numeri⿷匚⿳丨コ丨 data were used as given in a published report with the

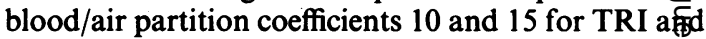
PER respectively. ${ }^{8}$ 
Three standard subjects were created. The first had a low amount of fat ( $1.5 \mathrm{~kg} ; 2 \%$ of the body weight), the second $10.7 \mathrm{~kg}(15 \%)$, and the third $25 \mathrm{~kg}$ fat $(30 \%)$.

The cardiac output was assumed to be $6.5 \mathrm{l} / \mathrm{min}$. The blood perfusion through the fatty tissues was 0.0261 / min.kg and $0.039,0.28$, and $0.78 \mathrm{l} / \mathrm{min}$ for the standard subjects respectively. The increase of total fat perfusion was assumed to decrease the perfusion through the vessel rich group (VRG); the slimmest person was assumed to have the highest VRG bloodflow. For PER the liver was included in the VRG and the VRG bloodflow in the three standard subjects was 4.95-5.45 $1 / \mathrm{min}$. For TRI the VRG did not include the liver and the VRG bloodflow was $3.35-3.851 / \mathrm{min}$. The alveolar ventilation was assumed to be $6 \mathrm{l} / \mathrm{min}$ and bloodflow through the liver and muscle group 1.6 and $1.02 \mathrm{l} / \mathrm{min}$ respectively.

\section{HEPATIC AND PULMONARY CLEARANCE}

The pulmonary clearance $\left(\mathrm{Cl}_{\text {pul }}=\dot{\mathrm{V}}_{\mathrm{a}} / \lambda\right)$ may be calculated by dividing the functional alveolar ventilation by the blood/air partition coefficient. The functional alveolar ventilations $\dot{\mathrm{V}}_{\mathrm{a}}$ and $\dot{\mathrm{V}}_{\mathrm{a}}{ }^{*}$ during and after exposure respectively were defined and calculated as in a previous paper. ${ }^{10}$ The individual $\dot{\mathrm{V}}_{\mathrm{a}}{ }^{*}$ was calculated as the time weighted postexposure ventilation of the inert PER: $\dot{\mathrm{V}}_{\mathrm{a}}^{*}$ equals the total PER uptake divided by the postexposure area under the $\mathrm{C}_{\mathrm{alv}, \mathrm{eq}}$ curve. It is assumed that PER is not bound to the organs or tissues. The $\dot{\mathrm{V}}_{\mathrm{a}}{ }^{*}$ was in the range of $6 \cdot 1-8 \cdot 2 \mathrm{l} / \mathrm{min}$ and 4.1-6.8 $1 / \mathrm{min}$ for the men and women respectively (table 1). The $\dot{\mathrm{V}}_{\mathrm{A}}$ and $\dot{\mathrm{V}}_{\mathrm{A}}{ }^{*}$ values of TRI have been set equal to those of PER. ${ }^{10}$ The $\mathrm{Cl}_{\text {pul }}$ of TRI during and after exposure will then be $1 \cdot 5$-fold higher than those of PER because of their partition coefficients of 10 and 15 respectively. For both PER and TRI, a weighted pulmonary clearance $\left(\overline{\mathrm{Cl}}_{\mathrm{pu}}\right)$ was defined because of the different levels of alveolar ventilation during and after exposure due to physical exercise (eq 2.8 appendix 3 ). For the inert PER the $\overline{\mathrm{Cl}}_{\mathrm{pul}}$ is proportional to the reciprocal of the area (AUC) under the unit impulse response: $\overline{\mathrm{Cl}}_{\mathrm{pul}}=1 /(\mathrm{AUC} \times \lambda)$. The weighted total body clearance (TBC) (eq 2.7) for PER has been set equal to the weighted $\mathrm{Cl}_{\text {pul }}$.

The apparent hepatic clearance $\left(\mathrm{Cl}_{\text {hep }}\right)$ of TRI has been calculated as the total amount metabolised divided by the total area under the arterial blood concentration curve. The total amount metabolised was set equal to the total not-exhaled amount. The area under $\mathrm{C}_{\mathrm{ar}}$ was estimated as described in appendix 3. The method of calculating the $\mathrm{Cl}_{\text {hep }}$ (eq 3.1 ; appendix 3) appears suitable to determine the changes in $\mathrm{Cl}_{\text {hep }}$ due to exercise during exposure. Despite the short exposure period of 30-60 minutes relative to the total observation period of up to 200 hours, the area under $\mathrm{C}_{\mathrm{ar}}$ during exposure is about $60 \%$ of the entire area (eqs $3.2 \mathrm{a}, \mathrm{b}$ ). For TRI the TBC is not simply the sum of $\mathrm{Cl}_{\mathrm{pul}}$ and $\mathrm{Cl}_{\text {hep }}$ because the clearances are in series and not in parallel (eq 3.6, appendix 3).

\section{STATISTICAL MOMENTS}

Kinetic analysis of the concentration time course was carried out using statistical moments: the area under the curve AUC, the mean residence time (MRT), and the variance of the MRT being the zero, first normal, and second central moments respectively. ${ }^{23}$ The MRT may be defined as the mean time for the intact molecules to journey through the body: it refers to a composite of all kinetic processes. The concentration time profiles of the alveolar concentration are expressed as a sum of exponential terms, therefore the AUC and MRT may easily be calculated. To calculate the MRT the TBC is usually set to be constant and only the time course of the concentration in blood has to be measured (eqs 4.1, 4.3). In our experiments with exercise the $\mathrm{Cl}_{\text {pul }}$ during exposure exceeds the postexposure $\mathrm{Cl}_{\text {pul }}$ three to fivefold. In this case eq 4.8 has to be used in which a correction term has been applied. This term requires knowledge of the alveolar ventilations $\dot{\mathrm{V}}_{\mathrm{a}}$ and $\dot{\mathrm{V}}_{\mathrm{a}}{ }^{*}$, whereas for the metabolising TRI also the cardiac output is required. The dependence of the MRT on an estimated cardiac output will be considered.

The steady state volume of distribution $\left(\mathrm{V}_{\mathrm{dss}}\right)$ has been calculated as the product of the MRT and TBC. ${ }^{15}$ The variance of the MRT was not evaluated because its physiological meaning is still questionable. Moreover, calculation of this variance may be subject to serious computational errors.

\section{Statistics}

The $\mathrm{C}_{\text {alveq }}$ data were fitted to a sum of exponential terms (eq $4.2 \mathrm{a}, \mathrm{b})$. The coefficient c(i) and exponents r(i) were estimated by minimising the sum of weighted squared deviations (WSS):

$$
W S S=\sum_{i}^{n}\left(\left(y_{i}-\hat{y}_{i}\right) / \hat{y}_{i}\right)^{2}
$$

where $n$ is the number of data points, and $y_{i}$ and $\hat{y}_{i}$ are the measured and predicted values respectively.

The standard deviation of the $\mathrm{C}_{\text {alv }}$-data around the fitted curve was estimated as:

$$
\mathrm{sd}=\sqrt{\mathrm{WSS} /(\mathrm{n}-\mathrm{k})}
$$

where $\mathbf{k}$ is the number of parameters to be estimated.

The number of exponential terms was chosen on the basis of two criteria, the first being the Akaike Information Criterion (AIC) ${ }^{16}$

$$
\mathrm{AIC}=\mathrm{n} \cdot \ln (\mathrm{WSS})+2 \mathrm{k}
$$


where $\mathrm{k}$ is the number of parameters to be estimated. The number of exponential terms yielding the lowest AIC was considered the best representation of the experimental data.

The second criterion was a statistical comparison of the fits by the $\mathrm{F}$ ratio test ${ }^{17}$ :

$$
F_{q-p, n-q}=\left(W_{S S} / W_{S S}-1\right)(n-q) /(q-p), p<q
$$

where $\mathrm{WSS}_{\mathrm{p}}$ and $\mathrm{WSS}_{\mathrm{q}}$ are the weighted sums of squared deviations obtained by fitting equations with $\mathrm{p}$ and $\mathrm{q}$ parameters respectively. The calculated $\mathrm{F}$ may be compared with the critical value derived from a table. This test indicates whether WSS is reduced significantly $(p<0.05)$ by the addition of one exponential to the fitting function.

Several kinetic parameters such as $\mathrm{t}_{\mathrm{i}(\mathrm{z})}, \mathrm{MRT}, \mathrm{AUC}$, and $\mathrm{Cl}_{\text {hep }}$ were calculated from the estimated $\mathrm{c}(\mathrm{i})$ and r(i) (appendix 4); these parameters are, therefore, sensitive to errors in $\mathrm{c}(\mathrm{i})$ and $\mathrm{r}(\mathrm{i})$.

To estimate the standard errors in the kinetic parameters the following procedure was carried out in some experiments. Normal random error terms with a mean of zero and the observed standard deviation were added to all the observed concentrations. This procedure was carried out ten times resulting in ten data sets. Curve fitting was carried out on each data set, and ten sets of estimated $\mathrm{c}(\mathrm{i})$ and $\mathrm{r}(\mathrm{i})(\mathrm{i}=1,2, \ldots)$ were derived. Subsequently, the kinetic parameters were calculated ten times with their mean and coefficient of variation (CV).

\section{Results}

\section{CUR VE FITTING}

For PER in most experiments the curve fitting to the $\mathrm{C}_{\text {alv }}$-data required five exponential terms. For TRI in about half the experiments the curve fitting required four exponential terms because the goodness of fit did not improve when using five terms. In most cases AIC and the $F$ ratio test yielded the same decisions regarding the number of terms. If not, AIC was used.

The terminal $t_{i(2)}$ appears to be more sensitive to the number of exponential terms in the curve fitting than the MRT. In all experiments with PER, curve fitting with five instead of four terms increases the $t_{t(z)}$ and MRT on average $1 \cdot 25$-fold (1-2.0) and 1.1-fold (1$1 \cdot 25)$ respectively. For TRI the average increases for $t_{y_{(2)}}$ were 3.7-fold (1-14.5) and for MRT, 1.27-fold $(1-2 \cdot 8)$.

In general the magnitude of error in the calculated individual kinetic parameters depends on the total observation period in which sampling is carried out and on the precision and accuracy of the data.

To estimate the errors in kinetic parameters such as $\mathrm{t}_{\mathrm{l}(\mathrm{z})}$, MRT, AUC, and $\mathrm{Cl}_{\text {hep }}$, use was made of normal random errors added to all the measured concentra tions at the $30 \mathrm{~W}$ exercise experiment of subject $4 \mathrm{f}$. F $\overrightarrow{\mathrm{r}}$ PER and TRI normal error was generated in the ranges of $5-8 \%$ and $8-12 \%$, respectively. These percentages were chosen because they agree with the observed standard deviation of the $\mathrm{C}_{\mathrm{alv}, \mathrm{eq}}$-data aroune the fitted curve. Generally, PER appears to require a observation period of more than 250 hours wheres TRI required a period of more than 150 hours. The observation periods yielded estimates of the kinetic parameters with a CV of less than $10 \%$. In general the MRT is less sensitive to changes in the observation period than the $t_{t(2)}$.

The AUC, $\mathrm{Cl}_{\text {pul }}$, and $\mathrm{Cl}_{\text {hep }}$ are not sensitive to errow in $\mathrm{C}_{\mathrm{al}, \mathrm{eq}}$ with these observation periods. The e periments with shorter observation periods we examined with the applied random errors. The kinet parameters with an estimated $\mathrm{CV}>20 \%$ will be indicated with an added circle (figs 1,2 ).

\section{KINETIC DATA OF PER}

For PER the individual kinetic parameters are pre sented in table 2. The $\mathrm{Cl}_{\text {hep }}$ has been set to zero and therefore the weighted total body clearance (TBE) equals the weighted $\mathrm{Cl}_{\text {pul }}(=1 /$ AUC. $\lambda)$. TBC is $0.2 T^{\mathbb{D}}$ $0.64 \mathrm{l} / \mathrm{min}$ (table 2). In the exercise experiments the weighted TBC is higher because of the increase of $\mathrm{Cl}_{\mathrm{pu}}^{\stackrel{\mathbb{Q}}{\mathrm{T}}}$ during exposure.

Table 2 Kinetic data of PER: weighted total body clearince $(\overline{T B C})$, terminal half time $\left(t_{1 / 2}\right)$, mean residence time $(M R T)$, and steady state volume of distribution $\left(V_{d s s}\right)$

\begin{tabular}{|c|c|c|c|c|c|c|}
\hline Subject & Watt & $t_{\text {obs }}$ & $\begin{array}{l}\overline{T B C} \\
(l / \min )\end{array}$ & $t_{1(z)}$ & $\begin{array}{l}M R T \\
(h)\end{array}$ & $\begin{array}{l}V_{d e s} \\
(l)\end{array}$ \\
\hline $\operatorname{lm}$ & $\begin{array}{r}0 \\
0 \\
30 \\
65\end{array}$ & $\begin{array}{l}240 \\
190 \\
310 \\
380\end{array}$ & $\begin{array}{l}0.47 \\
0.47 \\
0.51 \\
0.63\end{array}$ & $\begin{array}{r}98 \\
92 \\
133 \\
100\end{array}$ & $\begin{array}{r}101 \\
88 \\
99 \\
90\end{array}$ & $\begin{array}{l}2880 \\
2460 \\
3570 \\
3460\end{array}$ \\
\hline $2 \mathrm{~m}$ & $\begin{array}{l}0 \\
0\end{array}$ & $\begin{array}{r}170 \\
70\end{array}$ & $\begin{array}{l}0.48 \\
0.41\end{array}$ & $\begin{array}{c}80 \\
115 t\end{array}$ & $\begin{array}{c}59 \\
107+\end{array}$ & $\begin{array}{l}1690 \\
2600+\end{array}$ \\
\hline $3 \mathrm{~m}$ & $\begin{array}{r}0 \\
30 \\
65\end{array}$ & $\begin{array}{l}310 \\
265 \\
310\end{array}$ & $\begin{array}{l}0.41 \\
0.48 \\
0.64\end{array}$ & $\begin{array}{l}113 \\
148 \\
113\end{array}$ & $\begin{array}{l}85 \\
84 \\
76\end{array}$ & $\begin{array}{l}2060 \\
2410 \\
2920\end{array}$ \\
\hline $4 m$ & $\begin{array}{r}0 \\
30 \\
65\end{array}$ & $\begin{array}{l}240 \\
480 \\
240\end{array}$ & $\begin{array}{l}0.48 \\
0.57 \\
0.61\end{array}$ & $\begin{array}{r}62 \\
127 \\
55\end{array}$ & $\begin{array}{l}39 \\
38 \\
35\end{array}$ & $\begin{array}{l}1120 \\
1300 \\
1280\end{array}$ \\
\hline $\begin{array}{l}\text { If } \\
2 f\end{array}$ & $\begin{array}{l}0 \\
0 \\
0 \\
0\end{array}$ & $\begin{array}{l}185 \\
285 \\
260 \\
280\end{array}$ & $\begin{array}{l}0.44 \\
0.27 \\
0.29 \\
0.29\end{array}$ & $\begin{array}{l}103 \\
137 \\
122 \\
183\end{array}$ & $\begin{array}{r}74 \\
109 \\
104 \\
156\end{array}$ & $\begin{array}{l}1940 \\
1740 \\
1800 \\
2690\end{array}$ \\
\hline $3 f$ & $\begin{array}{c}0^{*} \\
30 \\
65\end{array}$ & $\begin{array}{r}24 \\
260 \\
380\end{array}$ & $\begin{array}{l}0.50 \\
0.60\end{array}$ & $\begin{array}{l}106 \\
122\end{array}$ & $\begin{array}{l}95 \\
91\end{array}$ & $\begin{array}{l}2850 \\
3270\end{array}$ \\
\hline $4 f$ & $\begin{array}{r}0 \\
30 \\
65\end{array}$ & $\begin{array}{l}240 \\
310 \\
410\end{array}$ & $\begin{array}{l}0.32 \\
0.42 \\
0.47\end{array}$ & $\begin{array}{l}134 \\
134 \\
127\end{array}$ & $\begin{array}{r}96 \\
78 \\
108\end{array}$ & $\begin{array}{l}1860 \\
1940 \\
3040\end{array}$ \\
\hline $5 f$ & $\begin{array}{r}0 \\
30 \\
65\end{array}$ & $\begin{array}{l}410 \\
360 \\
500\end{array}$ & $\begin{array}{l}0.44 \\
0.46 \\
0.41\end{array}$ & $\begin{array}{l}251 \\
113 \\
130\end{array}$ & $\begin{array}{l}136 \\
112 \\
102\end{array}$ & $\begin{array}{l}3380 \\
2510 \\
2320\end{array}$ \\
\hline
\end{tabular}

*Experiment stopped: subject visited dry cleaning shop. + Estimated coefficient of variation $>20 \%$. $\mathrm{t}_{\mathrm{obs}}=$ Observation period.

$\overline{\mathrm{TBC}}=1 /($ AUC. $\lambda)=\overline{\mathrm{CL}}_{\mathrm{pul}}$. 
At rest, at $30 \mathrm{~W}$, and at $65 \mathrm{~W}$ experiments the $t_{1(2)}$ shows ranges of $62-251$ hours $(\bar{x}=125), 106-148$ hours $(\overline{\mathrm{x}}=127)$, and 55-130 hours $(\overline{\mathrm{x}}=108)$ (table 2). In the $30 \mathrm{~W}$ experiments the $t_{t(z)}$ is a $0.45-2$-fold $(\overline{\mathrm{x}}=1.23)$ longer than at rest; in the $65 \mathrm{~W}$ experiments the $t_{t(2)}$ is somewhat shorter than at rest $(0 \cdot 45-1 \cdot 15$ fold; $\overline{\mathbf{x}}=0.87$ ).

For all subjects at rest, 30 , and $65 \mathrm{~W}$ the MRT is $35-$ 156 hours $(\bar{x}=95 ; n=11), 38-113$ hours $(\bar{x}=84.4$; $n=6)$, and 35-108 hours $(\bar{x}=84 ; n=6)$. On average, the MRT appears independent of the conditions during exposure; in the experiments with exercise it is 0.96 -fold $(0.75-1.12)$ shorter than in those at rest.

In general the MRT is about $25 \%$ shorter than the $t_{1(z)}$; the MRT/t $t_{1(z)}$-ratio is in the range of $0.3-1.03$ $(\overline{\mathrm{x}}=0.75)$. The intraindividual variation in the MRT appears to be less than that of the $t_{t(z)}$ (table 2).

The $\mathbf{V}_{\text {dss }}$ determined at experiments at rest appears to be about $30 \%$ less than the $V_{\text {dss }}$ in an experiment with physical exercise. The distribution volume is in the range of $1120-35701$.

\section{KINETIC DATA OF TRI}

In three experiments with two subjects the inhaled concentration was rather low and, therefore, the observation period was only about 48 hours. These data are not included in the kinetic analysis and are indicated with brackets (table 3). For TRI the weighted $\mathrm{Cl}_{\text {pul }}$ (eq 3.8 , appendix 3 ) is estimated as $0.53-1.48 \mathrm{l} / \mathrm{min}$.

The $\mathrm{Cl}_{\text {hep }}$ is in the range of $0.53-1.7 \mathrm{l} / \mathrm{min}$; one woman (4f) shows a relatively low $\mathrm{Cl}_{\text {hep }}$ of $0.53-0.83$ $1 / \mathrm{min}$. The $\mathrm{Cl}_{\text {hep }}$ appears independent of the level of exercise during exposure. The weighted TBC is in the range of $1 \cdot 2-3 \cdot 1 \mathrm{l} / \mathrm{min}$. For both the $\mathrm{Cl}_{\text {hep }}$ and the TBC the intrasubject variation is about $\pm 20 \%$.

At rest, 30 , and $65 \mathrm{~W}$ exercise experiments the $t_{\mathrm{t(z)}}$ shows ranges $21-29$ hours $(\bar{x}=24 \cdot 6 ; n=4), 14-55$ hours $(\bar{x}=38 ; n=6)$, and $13-63$ hours $(\bar{x}=35 ; n=5)$ respectively. The MRT is $2 \cdot 7-7 \cdot 9$ hours $(\bar{x}=5), 3 \cdot 4-22$ hours $(\bar{x}=11 \cdot 5)$, and $2 \cdot 7-12$ hours $(\bar{x}=9 \cdot 2)$. The MRT and the $t_{f(2)}$ at the experiments with physical activity are higher than at rest. In general, MRT and $t_{t(z)}$ do not appear to depend on the 30 or $65 \mathrm{~W}$ level of exercise. Therefore these two parameters at exercise are combined and a comparison is made with them at rest. The MRT during exercise is 0.98-3.1-fold $(\overline{\mathrm{x}}=1.92)$ higher than at rest. The increase of $t_{t(2)}$ is less pronounced: $0.53-2.8$-fold $(\overline{\mathrm{x}}=1.62)$. As mentioned in the methods section, the equation of the MRT of TRI (eq 4.8 appendix 4) contains a correction term which requires an estimate of the cardiac output ( $Q$ ). The calculated MRT appears not to be sensitive to fluctuations in $\mathbf{Q}$. A decrease of $Q$ from 6.5 to $51 / \mathrm{min}$ caused a change of MRT of only $1 \%$. During exposure, the increase of $Q$ from 6.5 up to $101 / \mathrm{min}$ showed a decrease of MRT of only $2-3 \%$.

In general, the MRT is far lower than the $t_{t(2)}$; the $\mathrm{MRT} / \mathrm{t}_{\mathrm{t}(2)}$-ratio is in the range of 0.11-0.66 ( $\left.\overline{\mathrm{x}}=0.28\right)$. Both the MRT and the $V_{\text {dss }}$ determined at rest are less than during exposure with physical exercise. The $V_{\mathrm{dss}}$ is in the range of 420-3100 $\mathrm{l}$.

PREDICTIONS OF THE $C_{\text {alv }}$ TIME COURSE

For both PER and TRI in each subject two or three independent predictions were carried out with

Table 3 Kinetic data of TRI: weighted total body clearance $(\overline{T B C})$, apparent hepatic clearance $\left(C_{\text {hep }}\right)$, weighted pulmonary clearance $\left(\overline{C l}_{p u l}\right)$, terminal half time $\left(t_{t(z)}\right)$, mean residence time $(M R T)$, and steady state volume of distribution ( $\left.V_{\text {dss }}\right)$

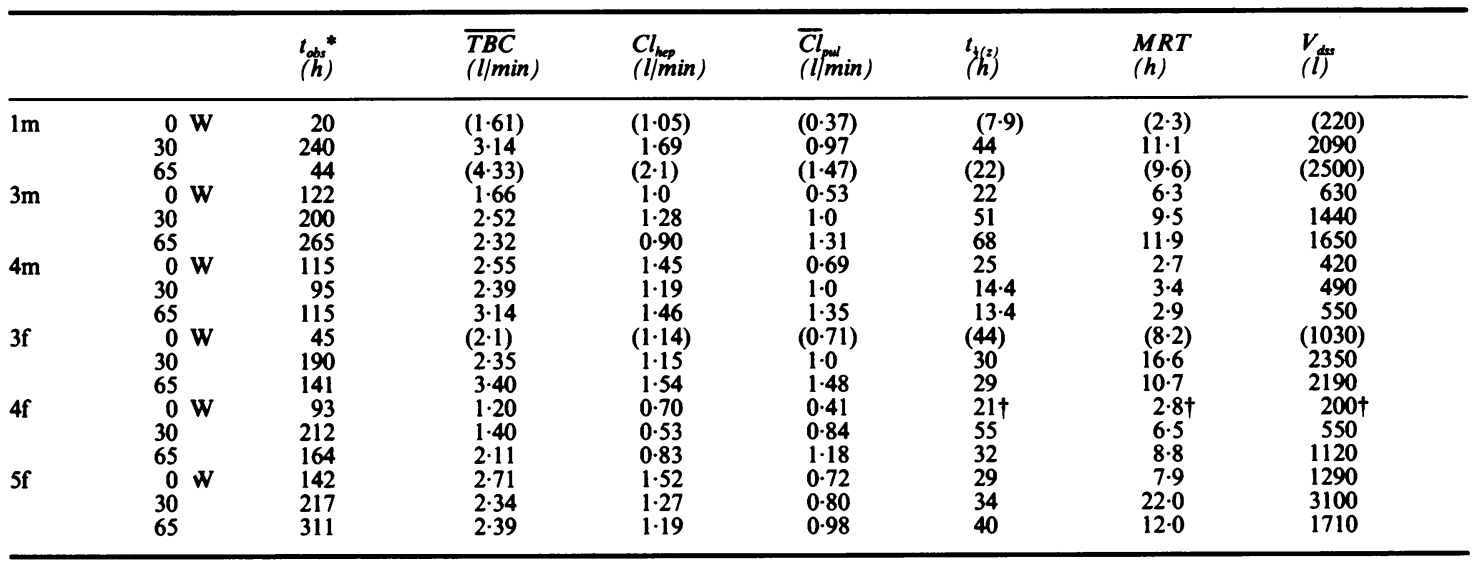

* $\mathrm{t}_{\mathrm{obs}}=$ Observation period.

$\dagger$ Estimated coefficient of variation $(\mathrm{CV})>20 \%$.

()$=$ Experiment with short observation period $(<48 \mathrm{~h})$. 
repeated exposure up to five weeks (five days a week). The workshifts lasted eight hours and so the exposure pattern was $5 \times(5 \times 8)$ hours. For all subjects the predictions were carried out with the same inhaled concentrations $\left(C_{1}\right)$ but with the individual alveolar ventilation $\left(\dot{\mathrm{V}}_{\mathrm{a}}\right)$. As mentioned, the individual $\dot{\mathrm{V}}_{\mathrm{a}}$ was indirectly measured ${ }^{10}$ (method section) and indicates the time weighted alveolar ventilation during normal daily life. Therefore, each subject had his own rate of functional intake $\left(\mathrm{RFI}=\mathrm{C}_{\mathrm{I}} \cdot \dot{\mathrm{V}}_{\mathrm{a}}\right)$ and his own pulmonary clearance $\left(=\dot{\mathrm{V}}_{\mathrm{a}} / \lambda\right)$. In the predictions the subjects are assumed to follow their normal daily life style. It should be realised that the predictions are based on the individual impulse responses that are experimentally determined during and after exposure. The exposure conditions differed: rest, $30 \mathrm{~W}$, and $65 \mathrm{~W}$ exercise.

At four points in time the predicted individual $\mathrm{C}_{\mathrm{alv}, \mathrm{oc}}$ relative to $C_{I}$ are graphically presented as a function of the amount of fat (fig $1 \mathrm{a}, \mathrm{b}, \mathrm{c}, \mathrm{d}$ ). Figure $1(a)$ shows $\mathrm{C}_{\mathrm{al}, \mathrm{eq}}$ at 24 hours (Tuesday morning) after eight hours exposure and 16 hours non-exposure; fig $1(b)$ concerns the cumulation at the next Monday morning after $5 \times 8$ hours exposure and a weekend non-exposure; fig 1 (c) shows the $C_{\text {alv,eq }} / C_{I}$ at the end of exposure on Friday of the fifth week and fig $1(d)$ shows the cumulation at Monday morning in the sixth week. The lines show the predictions for standard subjects derived from a simulation model ${ }^{8}$; the alveolar ventilation was chosen as $6 \mathrm{l} / \mathrm{min}$. These predictions cover a 2-25 kg fat; therefore, they are able to show a more pronounced relation with the amount of fat than our predictions based on the subjects.

\section{PER PREDICTIONS}

For PER at the three points of time after exposure (fig $1 \mathrm{a}, \mathrm{b}, \mathrm{d})$ the predicted $\mathrm{C}_{\mathrm{al}, \text {,eq }} / \mathrm{C}_{1}$ values are in the range of $0.026-0.057,0.04-0.088$, and $0.053-0.125$, respectively. At all three points of time the intrasubject variation in the predictions is small: $\bar{x} \pm 10 \%$. The intersubject variation in the cumulation is about twofold. After only eight hours exposure the man with $7.3 \mathrm{~kg}$ fat appears to have the highest $\mathrm{C}_{\mathrm{alv}, \mathrm{eq}}$ whereas after $5 \times(5 \times 8)$ hours this slim subject has a relative low accumulation (fig $1 \mathrm{a}, \mathrm{d}$ ). This pattern of $\mathrm{C}_{\mathrm{alv}, \mathrm{eq}}$ corresponds to the prediction made by the simulation model. On the other hand, the man $1 \mathrm{~m}$ with $22.5 \mathrm{~kg}$ fat shows a relative high $\mathrm{C}_{\text {alv,eq }}$ at all three points in time.

On the second Monday morning after one week of exposure the accumulation is not complete and a further week of exposure still increases the $C_{a l v, e q}$ after the weekend. It was shown in all subjects that with this pattern of exposure, the completion of accumulation on Monday morning has been achieved after five weeks.

The differences in the individual $\mathrm{C}_{\mathrm{alv}, \mathrm{eq}}$ levels at the second and sixth Monday morning reflect the differ- ences in the individual rate of accumulation. The sli subject $4 \mathrm{~m}(\square)$ appears to have little increase whereas for subject 1f $(\square)$ a 2.5-fold increase in concentratiog is predicted in the next four weeks (fig $1 b, d$ ).

The level of accumulation after five weeks $\overline{\partial f}$ exposure appears to be more strongly related to the amount of fatty tissues than that after one week (figd b, d).

At the end of exposure on the Friday of the fif week $C_{a l v, e q} / C_{I}$ is $0.32-0.63$ (fig $1 \mathrm{c}$ ). For all subjects the rest impulse responses yield the highest predictions. At the weekend the slim subject $(4 \mathrm{~m})$ shows a predicted decline of about eightfold whereas for subject $1 \mathrm{~m}-\vec{a}$ decline of 3.5-fold is predicted (fig $1 \mathrm{c}, \mathrm{d}$ ).

\section{TRI PREDICTIONS}

At the three points of time after exposure (fig $1 \mathrm{a}, \mathrm{b}, \mathrm{d}$ ) the $\mathrm{C}_{\mathrm{alv}, \mathrm{og}} / \mathrm{C}_{1}$ is in the range of 0.0045-0.011, 0.0005 0.01 , and $0.0005-0.01$ respectively.

For the men the intrasubject variation in the predicted TRI concentration at the next morning after eight hours exposure is about $\overline{\mathbf{x}} \pm 20 \%$ (fig la). Th $\overrightarrow{\mathrm{e}}$ women appear to have larger variability $(\overline{\mathrm{x}} \pm 30 \mathrm{D}$ $50 \%$ ). After five days of exposure the intrasubjea variation increases. For two men the three predictiong yield $\bar{x} \pm 20 \%$; for the other man two predictions ate doubtful because the observation periods in the experiments were only 20 and 44 hours (sympog within brackets). For the women only two predictions appear to be close, the other one is twofold too ligh (subject 3f, 5f) or fourfold too low (subject 4f). The predictions based on the impulse responses from the rest experiments yield the lowest predictions (symbog with added point). In general the $\mathrm{C}_{\mathrm{alv}, \mathrm{eq}}$ on the Monday morning of the sixth week is little higher than after onf week; for TRI the rate of accumulation appears to be small after one week.

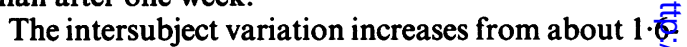
fold (fig la) to 10-fold (fig 1b, d). At all three times the slim subject $(4 \mathrm{~m})$ has a relative low $C_{\text {alv,eq }}$ value. On the next morning after eight hours exposure (fig 1a) out predictions are about twofold higher than those of the simulation model (broken lines). After one or five weeks of repeated exposure our predictions for the slim subject are threefold lower than the prediction of the simulation model. In the range of $12-25 \mathrm{~kg}$ fat the results of the simulation model agree with our predics tions. At the end of exposure on the Friday of the fifti. week the $C_{\text {alv,eq }} / C_{1}$ is in the range of $0 \cdot 15-0 \cdot 46$. For a subjects the rest impulse response yields the highest prediction (symbols with added point; fig 1c). At the weekend the slim subject $(1 \mathrm{~m})$ shows a predictey decline of 80 -fold whereas the other subjects show decline of about 20 -fold. It is noteworthy that the $\mathrm{C}_{\mathrm{alv}} / \mathrm{C}_{\mathrm{I}}=0.15$ at the end of exposure is low. This 


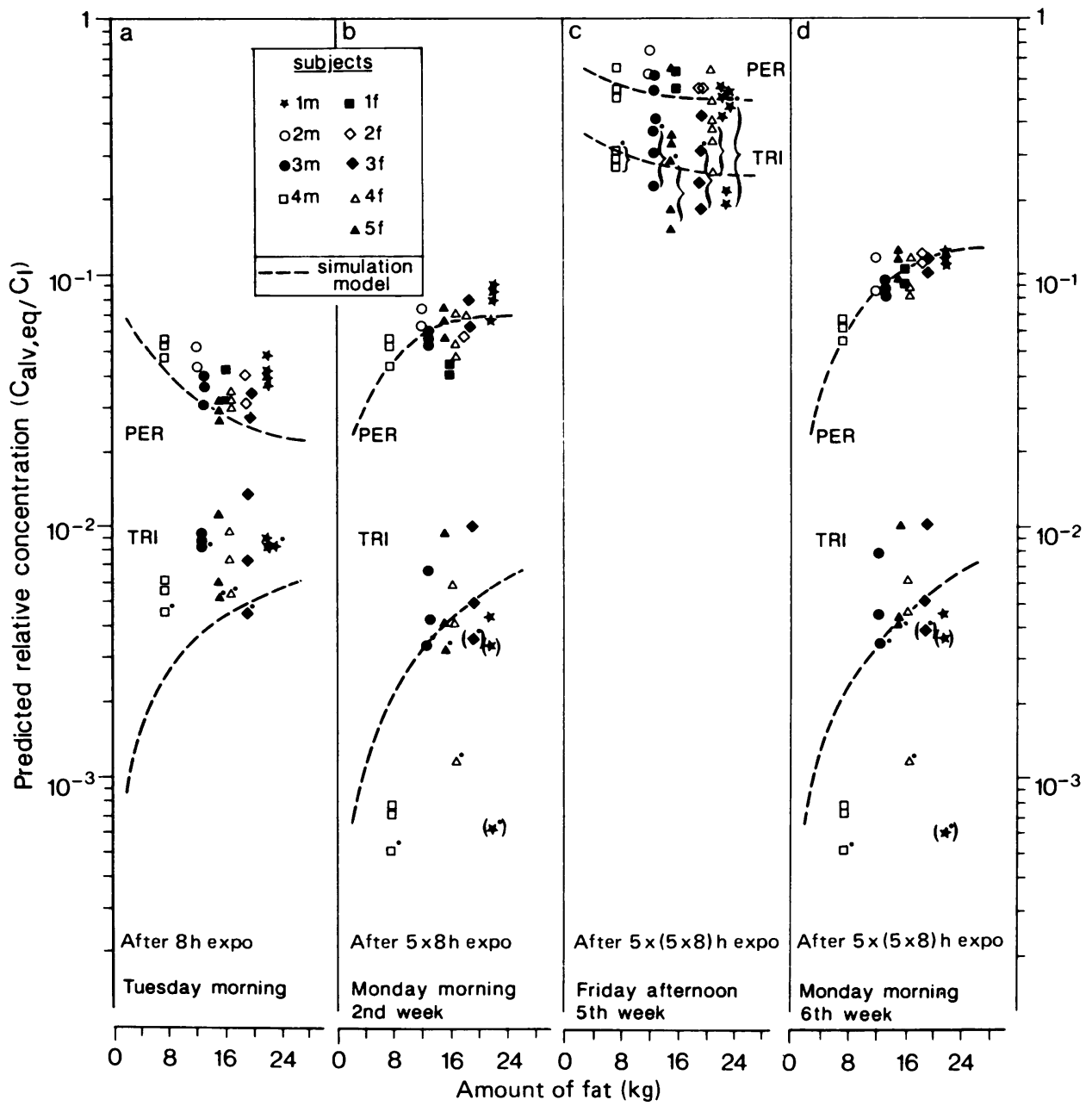

Fig $1 \mathrm{a}, \mathrm{b}, \mathrm{c}, \mathrm{d}$ Predicted individual $C_{\text {alveq }}\left(=C_{\text {ven }} / \lambda\right)$ relative to inhaled concentration for both PER and TRI on different points of time during five weeks of repeated exposure $5 \times(5 \times 8)$ hours. Each subject is presented by his symbols. For both PER and TRI in each subject two or three independent time courses of $C_{\text {alveq }}$ are predicted based on rest, $30 \mathrm{~W}$, and $65 \mathrm{Watt}$ experiments. All subjects are assumed to be exposed to same $C_{I}$ but with individual $\dot{V}_{a}$ estimated during normal daily life style; respiratory input equals $C_{I} . V_{a}$. Broken lines present predictions with a simulation model based on physiological assumptions $\left(\dot{V}_{a}=6 \mathrm{l} / \mathrm{min}\right)$. Symbol between parentheses: experiment with an observation period of less than 48 hours. Added point to symbol: $C_{\text {alveq }} / C_{I}$ of TRI prediction based on rest experiment.

value, however, is predicted with an impulse response from an exercise experiment.

ACCUMULATION AS FUNCTION OF $T_{\xi(z)}$ AND MRT Figures $2(a)$ and $2(b)$ show the level of accumulation on Monday morning after five weeks of repeated exposure as function of the $t_{t(2)}$ and MRT for both PER and TRI. For both the level of accumulation correlated better with the MRT $\left(\log \left(\mathrm{C}_{\text {alv,eq }}\right) v \log\right.$ -
(MRT); $\mathbf{R}^{2}=\mathbf{0 . 7 5}$ and $\mathbf{0 . 8 8}$ respectively) than with the terminal $t_{1}\left(\log \left(C_{a l v, q q}\right) v \log \left(t_{t(2)}\right) ; R^{2}=0.16\right.$ and 0.45 respectively).

\section{Discussion}

PREDICTION OF THE INDIVIDUAL TIME COURSES When two of the three functions (rate of input, kinetic response, or unit impulse response) are known the 

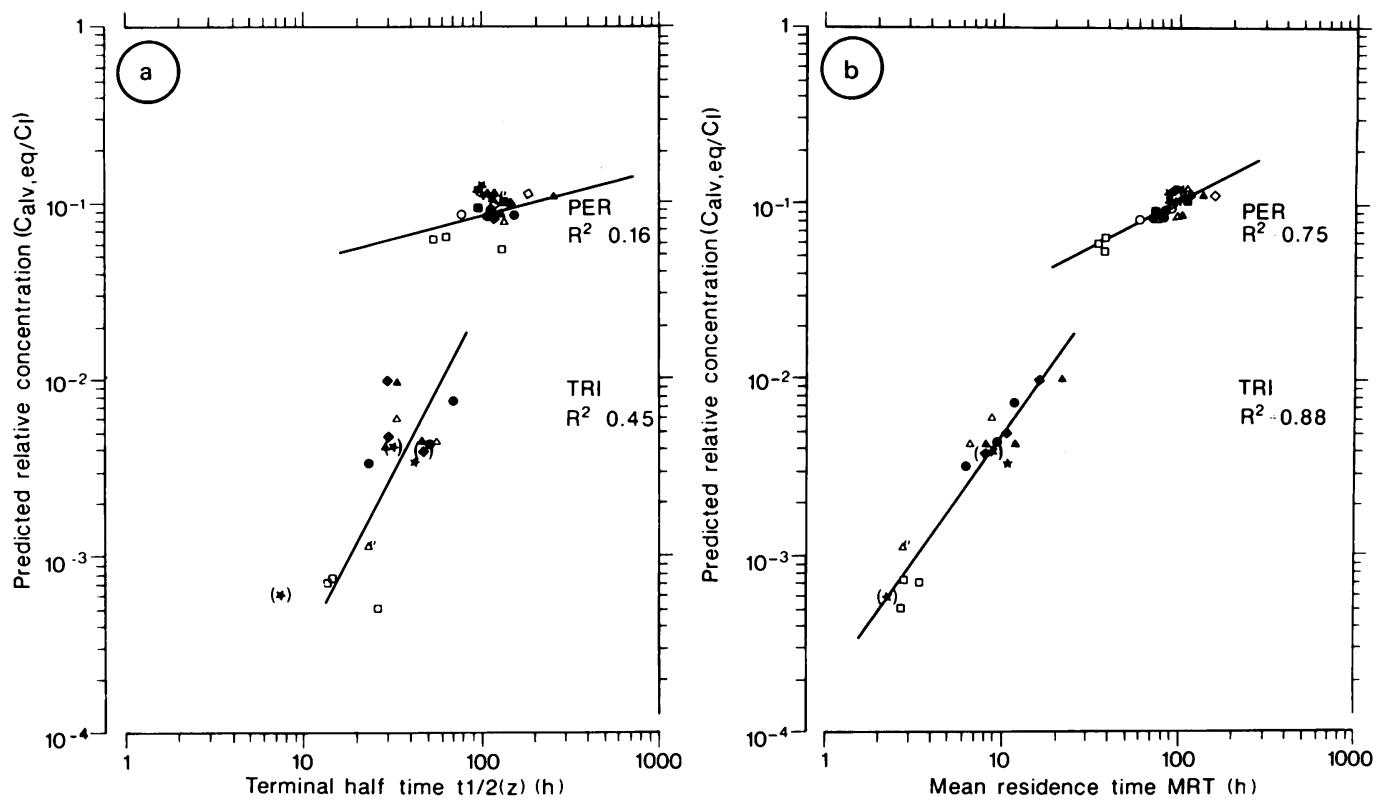

Fig 2a, b Log-log presentations of the predicted $C_{\text {alveq }}$ relative to $C_{1}$ as function of the terminal half time (fig $\left.2 a\right)$ and mean residence time (fig $2 b) . C_{a l v, e q}$ has been predicted on Monday morning in sixth week (fig $1 \mathrm{~d}$ ). Each subject is presented by his symbols. PER: $\log \left(C_{a l v, e q} / C_{l}\right)=-1 \cdot 60+0 \cdot 28 \log t_{t(z)}$ and $\log \left(C_{a l v} / C_{l}\right)=-2 \cdot 0+0 \cdot 52 \log M R T(n=23), T R I$ : $\log \left(C_{a l v, e q} / C_{l}\right)=-4.52+1.37 \log t_{1 / 2)}$ and $\log \left(C_{a l v} C_{l}\right)=-5.42+1.92 \log M R T(n=14)$. Symbol between brackets: experiment with an observation period less than 48 hours. Added circle to symbol: $C V$ of the $M R T$ and $t_{t(z)}$ more than $20 \%$.

third may be calculated with a suitable method for convolution and deconvolution. ${ }^{1314}$ In a previous paper the individual respiratory intake was estimated. "In the present study the individual kinetic response in the blood was predicted with repeated exposure (eight hours a day, five days a week) during five weeks. For each subject an individual rate of functional intake (RFI) as rate of input at repeated exposure was applied and for both PER and TRI the predictions were mostly carried out three times. The predictions were based on the individual unit impulse responses determined at rest, 30 , and $65 \mathrm{~W}$ exercise during 30-60 minutes exposure.

In the hypothetical case that the kinetic processes in an individual do not change then the unit impulse response does not change and all three predictions for one individual would yield the same timecourse relative to the RFI. In fact, the intrasubject variation in the predictions reflects the variations in the kinetics.

At four points in time the intra and intersubject variations in the predictions have been evaluated. Three points were chosen as the next morning after eight hours of exposure, the second Monday morning after one week of repeated exposure, and the sixth Monday morning after five weeks of exposure. The predicted concentrations at these points of time will be considered as indicators of the accumulation with this particular regimen of exposure. A fourth point of tim was chosen at the end of exposure on Friday afternool in the fifth week.

\section{TETRACHLOROETHENE}

In all subjects the intrasubject variations of the predictions of $C_{\text {alv }}$ relative to inhaled concentration $G$ at the three mornings were small, within 5-15\% (fig 1 b, d). Physical exercise during exposure appears to. affect the unit impulse response so little that it is nof obvious at the three chosen points of time. At the en of exposure on Friday of the fifth week (fig 1c) exercise during the experiments does have an impact: for al subjects the rest impulse responses yielded a somewh higher prediction.

The intersubject variation on the next morning after eight hours of exposure the $C_{\text {alv }} / C_{I}$ level is $0.027-0.05$ to (fig 1a). After one week of repeated exposure on the्E second Monday morning $C_{\text {alv,ea }} / C_{1}$ is $0.04-0.09$ (fig $1 \mathrm{~b}$ ) whereas after five weeks on the sixth Monday morning $\mathrm{C}_{\text {alv }} / \mathrm{C}_{\mathrm{I}}$ is $0.054-0.12$ (fig $1 \mathrm{~d}$ ). For all subjects the $\mathrm{C}_{\mathrm{alv}, \mathrm{eq}} / \mathrm{C}_{\mathrm{I}}$ level hardly increased at the following 
Monday mornings after five consecutive weeks of exposure.

Only a few experimental studies with repeated exposure have been published. Subjects were repeatedly exposed to PER at rest during seven hours on each of five days. ${ }^{18}$ On Tuesday morning after the first seven hours exposure a mean exhaled concentration of $3.5 \%(2 \cdot 5-4.5 \%, n=15)$ of $C_{I}$ was measured. On the next Monday morning after $5 \times 7$ hours of exposure a mean concentration of $5 \%(2-7 \%, n=5)$ of $C_{1}$ was exhaled. Our predictions after eight hours and $5 \times 8$ hours exposure correspond well with these data: $3.8 \%$ $(2 \cdot 6-5 \cdot 4 \%)$ and $6 \cdot 3 \%(4 \cdot 3-8 \cdot 5 \%)$ were predicted (fig la, 1b).

In an industrial investigation the fall in the concentration in exhaled air was $4 \cdot 1$ and threefold for the slim and obese workers respectively. ${ }^{19}$ Our predicted decline of $\mathrm{C}_{\text {alv.e }}$ was about eight and 4-2-fold respectively (fig lc, d). The lower decrease in the industrial setting may be explained by the time point of sampling, which was 15-30 minutes after exposure.

\section{TRICHLOROETHENE}

For TRI the intrasubject variation in the predicted concentration appears to be substantial at all four points of time. Physical exercise during experimental exposure has an impact on the unit impulse response that becomes manifest in the predicted concentration. All predictions of the postexposure $\mathrm{C}_{\mathrm{alv}, \mathrm{eq}} / \mathrm{C}_{\mathrm{I}}(\mathrm{fig} \mathrm{la}, \mathrm{b}$, d) based on the impulse responses calculated from the exercise experiments yield higher predicted concentrations than those based on the rest impulse responses. At the end of exposure on Friday (fig lc), however, the rest impulse response yielded higher predictions.

After eight hours exposure at the next morning only for the men the intrasubject variation was within $10 \%$; the intrasubject variation for the women was even up to $50 \%$ (fig 1a).

The intersubject variation of $\mathrm{C}_{\mathrm{alv}, \mathrm{eq}} / \mathrm{C}_{\mathrm{I}}$ after eight hours exposure on the next morning was 0.005-0.013 (fig la). After one and five weeks of repeated exposure $\mathrm{C}_{\text {alv }} / \mathrm{C}_{1}$ was 0.0005-0.01 (fig $1 \mathrm{~b}$, d). At all three postexposure points of time the slim subject with $7 \cdot 3$ $\mathrm{kg}$ of fat showed relative low predictions of $\mathrm{C}_{\mathrm{alv}}$; on average this subject showed sevenfold lower concentration.

By contrast with PER, hardly any cumulation occurred in the period between the first and the fifth week of exposure (fig $1 \mathrm{~b}, \mathrm{~d})$. Stewart et al exposed six subjects at rest to repeated exposure to TRI of $5 \times 7$ hours. ${ }^{20}$ At two, 16, and 65 hours after the repeated exposure the mean concentrations as percentage of $\mathrm{C}_{1}$ were $3 \cdot 1 \%(2 \cdot 7-4 \cdot 5 \%), 0 \cdot 8 \%(0 \cdot 7-1 \cdot 5 \%)$, and $0 \cdot 16 \%$ $(0 \cdot 08-0 \cdot 24 \%)$. The predicted mean percentages after $5 \times 8$ hours exposure in the present study were $4.1 \%$ $(2 \cdot 4-5.7 \%), 1 \cdot 3 \%(0.55-2.9 \%)$, and $0.43 \%(0.05-1 \%)$.
These predictions were based on the unit impulse responses from the 17 rest and exercise experiments. Predictions based only on individual kinetics determined in the five rest experiments yielded 3.6\% (2.4$4.3 \%), 1 \%(0.54-1.48 \%)$, and $0.34 \%(0.05-0.63 \%)$. In general, the present predicted levels are higher; this may be partly explained by the use of eight instead of seven hour exposures. Our predicted intersubject range was about threefold larger than the measured range. ${ }^{20}$ This may indicate that the difference in the mean concentration may be due to the selection of the subjects. For both PER and TRI the cumulations predicted by the physiological simulation model $^{8}$ are more or less in agreement with our predictions. For example, after only eight hours exposure to TRI on Tuesday morning (fig la) our predicted concentrations are about twofold higher than those of the simulation model.

To find an explanation for the substantial intrasubject variation in the kinetics of TRI the impact of physical exercise on the following kinetic parameters has to be considered: hepatic clearance, pulmonary clearance, the mean residence time, and terminal half time.

HEPATIC AND PULMONARY CLEARANCE

In our experiments the hepatic clearance $\left(\mathrm{Cl}_{\text {hep }}\right)$ of TRI was in the range of $0.5-1.71 / \mathrm{min}$.

In published data some methods have been used to estimate the $\mathrm{Cl}_{\text {hep }}$ of TRI. A theoretical approach has been used in which numerical values of eg bloodflows have been assumed. ${ }^{21}$ In an exposure experiment after eight hours exposure, the rate of metabolism may be set equal to the rate of uptake minus an absorbed amount in the unsaturated fatty tissue. ${ }^{22}$ Furthermore, the terminal slope at 20 hours after exposure has been

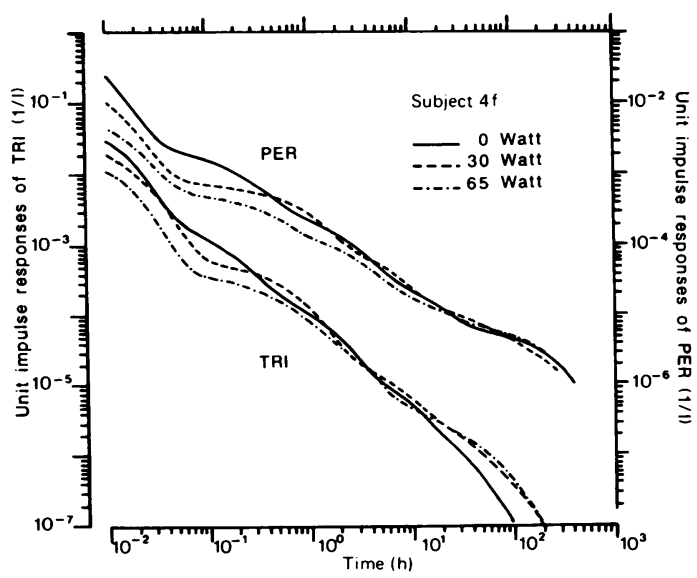

Fig 3 Log-log presentation of unit impulse responses for $T R I$ and PER for subject 4 from experiments at rest, $30 \mathrm{~W}$, and $65 \mathrm{~W}$ physical exercise. 
used with assumed values of $\mathrm{V}_{\mathrm{a}}$ and the distribution volume. ${ }^{23}$ In all three methods the $\mathrm{Cl}_{\text {hep }}$ of TRI at rest was estimated to be $1.5-2.01 / \mathrm{min}$. The magnitude of $\mathrm{Cl}_{\text {hep }}$ indicates that the hepatic elimination depends predominantly on hepatic blood flow and not on the metabolising enzyme activity (a solvent with a high extraction ratio). ${ }^{24}$

In general our calculated $\mathrm{Cl}_{\text {hep }}$ values are somewhat lower. In particular, for one subject the $\mathrm{Cl}_{\text {hep }}$ is less than $1 \mathrm{l} / \mathrm{min}$. In our experiments $\mathrm{Cl}_{\text {hep }}$ was calculated with eq 3.1 (appendix 3). The entire area under the $C_{a r t}$ was estimated and the total hepatic excretion was estimated from the not-exhaled fraction. The method appears to be suited to calculate $\mathrm{Cl}_{\text {hep }}$; however, the use of the total amount of all metabolites excreted in urine would be preferred.

The calculated $\mathrm{Cl}_{\text {hep }}$ was shown not to be significantly affected by exercise up to $65 \mathrm{~W}$. Hepatic blood flow is probably rather constant in the range of $0-65 \mathrm{~W}$ exercise because changes in liver flow will be reflected in $\mathrm{Cl}_{\text {hep }}$.

The $\mathrm{Cl}_{\text {pul }}$ is obviously affected by exercise. During exercise the alveolar ventilation increased two to fivefold and, therefore, the $\overline{\mathrm{Cl}}_{\mathrm{pul}}$

For TRI both changes in $\mathrm{Cl}_{\text {pu }}$ and $\mathrm{Cl}_{\text {hep }}$ are reflected in the TBC (table 3). The TBC at the exercise experiments appears to be the same or somewhat higher than at rest. A higher $\overline{\mathrm{TBC}}$ at the same rate of respiratory input causes a more rapid decline in the blood concentration; the accumulation with repeated exposure is less pronounced. The prediction of the accumulation of TRI in the blood when using the impulse response from the exercise experiments shows the opposite. It may be concluded that the variations in the weighted TBC are not able to explain the substantial intrasubject variation in the predicted concentration time course. The intrasubject variations in the terminal half time and the mean residence time are now considered.

TER MINAL HALF TIME AND MEAN RESIDENCE TIME The terminal half time $\left(t_{t_{(z)}}\right)$ and the mean residence time (MRT) are considered from a physiological point of view.

Distribution and elimination are competing processes for removal from the blood. The concentration time profile in blood may be divided into two phases. In the distribution phase the removal from the blood is mainly due to the distribution in the body whereas in the elimination phase the decline of the concentration in the blood is due to elimination. If distribution is rapid compared with elimination little solvent is lost during attainment of the "distribution equilibrium." If distribution is the slower process then much solvent is lost before the distribution equilibrium is achieved.

The terminal half time represents the rate of decline of the concentration due to elimination from the body when the distribution equilibrium has been achieved. $\frac{3}{3}$ The excreted amount in the distribution phase is not $\frac{}{\$}$ taken into account and, therefore, the $t_{t_{(z)}}$ does not indicate the amount in the body relative to the dose at which the rate of terminal decline occurs.

The MRT may be defined as the mean time for the $\frac{\bar{C}}{O}$ intact molecules to journey through the body and $\overline{\bar{c}}$. involves a composite of all kinetic processes. ${ }^{5}$ Once $a \widehat{\nabla}$ drug has entered the blood, the molecules circulate through the body in the bloodflow. The molecules maye be absorbed by a tissue or organ or eliminated by $\vec{D}$

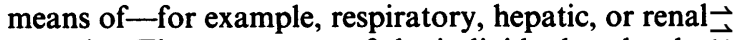
excretion. The movement of the individual molecules ${ }_{\sigma}$ through the body is governed by probability, since they will not all be metabolised or excreted at the same $\frac{\mathbb{}}{3}$ time. Each molecule has a certain residence time in the body which may be conceived of as a frequency? distribution with a MRT and a variance around the mean.

When the MRT is deduced from the concentration time profile in blood, it is possible to distinguish between the removal from the blood by elimination and distribution in the body. The rate of elimination ${ }_{\mathbb{\Phi}}$ shortens the MRT, whereas removal from the blood $\mathbb{\Phi}_{\mathbb{Q}}$ due to distribution in non-eliminating tissues causes a longer MRT. By contrast with the terminal half time@ $t_{1(z)}$ the MRT depends on the shape of the entire concentration time curve and is able to weigh theog distribution and the elimination phase.

Physical exercise increases the $\mathrm{Cl}_{\text {pul }}$ and this migy cause a higher rate of elimination $\left(=\mathrm{Cl}_{\mathrm{pul}} \cdot \mathrm{C}_{\mathrm{ven}}\right)$ and as a consequence a shorter MRT.

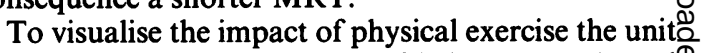
impulse response $g(t)$ may be of help. For PER and $\stackrel{\mathbb{Q}}{\complement}$ TRI both at rest and with physical exercise during $\vec{\circ}$ exposure, the unit impulse responses for one woman 3 are shown in fig 3 . In fact the $g(t)$ curve presents the concentration time profile in blood after a bolus: injection with a unit input. This implies that the impulse responses at the rest and exercise experiments ${ }_{3}^{\mathbb{\Phi}}$ are normalised to their rate of input - that is, the rate ${ }_{-}^{-}$ of functional intake (eq 4.6 appendix 4). The pul-3. monary clearance $\left(=\dot{\mathrm{V}}_{\mathrm{a}} / \lambda\right)$ during exposure takes partio in the kinetics, however, and it may affect the $g(t)-\frac{3}{3}$ curve when physical exercise is carried out. At 30 and $65 \mathrm{~W}$ exercise the $\mathrm{Cl}_{\mathrm{pul}}$ increases three to fivefold and ${ }^{\mathrm{P}}$ an increased pulmonary excretion $\left(=\mathrm{Cl}_{\mathrm{pu}} \cdot \mathrm{C}_{\mathrm{ven}}\right)$ mayo occur. At first sight this seems an important reason for the decreased $g(t)$ curve during the distribution phase $N$ up to 20 hours. The MRT would become shorter because of the extra number of molecules eliminated at an early stage.

The extra pulmonary excretion, however, is not significant, otherwise the $g(t)$ curve would be decreased in the whole observation period due to extra旡 
early removal from the body. In addition, for both PER and TRI the MRT at the exercise experiments is not shorter than the MRT at the rest experiment.

For PER it was shown that MRT at the exercise experiments is about the same as at rest. This suggests that an increased $\mathrm{Cl}_{\mathrm{pul}}$ during exercise does not result into an early extra elimination. This may be explained with the decreased $\mathrm{C}_{\text {ven }}$ relative to the respiratory input due to a more rapid distribution.

For TRI the MRT in the exercise experiment is longer than at rest. This suggests that rapid distribution dominates over the increased $\mathrm{Cl}_{\text {pul }}$ and elimination is delayed. By contrast with PER, the impact of $\mathrm{Cl}_{\mathrm{pul}}$ on the $\mathrm{TBC}$ is limited because $\mathrm{Cl}_{\text {hep }}$ is not zero and, therefore, an increase of $\mathrm{Cl}_{\text {pul }}$ will both increase the TBC and decrease the MRT to a minor extent. Moreover, a low blood concentration relative to the intake yields a smaller rate of hepatic excretion. Therefore, it may be expected that at exercise the elimination of TRI is more delayed than that of PER. The MRT/ $t_{t(z)}$ ratio may be a good indicator of the amount relative to the input still to eliminate in the terminal phase. When this ratio is about unity almost all the amount will be excreted in the terminal phase whereas a low ratio indicates that a substantial amount is excreted in the distribution phase. Therefore, the MRT/ $t_{t(2)}$ ratio may better predict the relative amounts excreted in the distribution and terminal phase. The MRT of TRI is about $70 \%$ shorter than the terminal $t_{t(z)}$. This indicates that for TRI a relative small amount still needs to be eliminated during the elimination phase.

These amounts may be estimated by means of the relative areas of the distribution and elimination phase of the unit impulse response according to eq 4.6 (appendix 4). For TRI and PER the percentages of the total excreted amount in the terminal phase may be estimated as $10-20 \%$ and $50-60 \%$ respectively. In particular for TRI changes in the excreted amount in the distribution phase due to, for example, physical exercise, greatly affect the amount excreted in the terminal phase and therefore a substantial intrasubject variation in the prediction of the cumulations seems plausible (fig 1).

\section{PREDICTION OF ACCUMULATION}

The MRT $/ \mathrm{t}_{1(2)}$ ratio is not suitable to predict accumulation with repeated exposure because a high ratio may be associated with both a short MRT and $t_{1(z)}$.

On the other hand, a long $t_{t(z)}$ is suitable to predict accumulation only when the MRT/t $t_{\text {(z) }}$ ratio is about unity. In other words the terminal $t_{t(z)}$ is suitable to predict accumulation only when the relative amount to eliminate with the terminal half time is substantial. It may be expected that the MRT is a better predictor of accumulation than the $t_{\frac{1}{(2)}}$ because the MRT characterises the entire concentration time course. For both PER and TRI the prediction of the accumulated concentration at Monday morning after five weeks of repeated exposure with the MRT $\left(R^{2}=0.75,0.88\right.$ resp) appears better than with $t_{t(z)}\left(R^{2}=0 \cdot 16,0 \cdot 45\right)$.

\section{DISTRIBUTION VOLUME}

The distribution volume at steady state $\left(\mathrm{V}_{\mathrm{dss}}\right)$ may be theoretically calculated with the use of the partition coefficients given in published data. For PER and TRI the most important partition coefficient is the fatblood coefficient and equals about 125 and 60 respectively. For PER the slim subject $4 \mathrm{~m}$ and the more adipose subject $1 \mathrm{~m}$ will have a theoretical $\mathrm{V}_{\text {dss }}$ of about 12501 and 36501 . For TRI these theoretical $V_{d s s}$ will be about 6801 and 17001 respectively. The calculated $V_{\text {dss }}$ from the experiments (tables 2 and 3) agree substantially with the calculated $V_{\text {dss }}$. Nevertheless, the $V_{\text {dss }}$ during the exercise experiments exceed the $V_{\text {dss }}$ at rest. This may suggest that in the rest experiments a complete distribution equilibrium was not achieved and that the calculated distribution volume is lower than the true $V_{\text {dss. }}$. It appears that some parts of the body are not completely involved in the storage of the solvent. This may be explained by the inhomogenity in the blood perfusion and diffusion in, for example, the subcutaneous fat.

Exercise may increase the subcutaneous blood flow and, therefore, the inhomogenity in perfusion may decrease and the distribution volume increases. An extra amount will be stored in subcutaneous fat which is usually not well perfused. For PER and TRI an increase of $V_{\mathrm{dss}}$ of $1000 \mathrm{l}$ corresponds to an extra perfused fatty tissue of about 81 and 161 respectively.

For TRI in particular the increase in the $V_{\text {dss }}$ seems at times too large and unreliable. It should be realised that the estimated $V_{\text {dss }}$ has been calculated as the product of the MRT and the weighted TBC and, therefore, the $V_{d s s}$ is sensitive to errors in both parameters.

It may be concluded that an increase of $V_{\text {dss }}$ due to physical exercise during exposure may occur but an accurate determination of the extra magnitude of $\mathbf{V}_{\mathrm{dss}}$ seems doubtful.

In an experimental study with volunteers repeatedly exposed over four to 10 days to $\mathrm{m}$-xylene it was found that a greater distribution to subcutaneous fat occurred when the volunteers performed $100 \mathrm{~W}$ physical exercise four times a day. ${ }^{25}$

\section{MODEL DEPENDANCE}

The $t_{t(z)}, A U C$, and the MRT are in principle model independent which means that these parameters may be calculated without the use of any kinetic model. The $t_{t(z)}$ may be obtained graphically from the slope in the 
terminal phase; MRT may be found by numerical integration of a sufficient number of data points.

For both the numerical and the analytical solution, however, the extrapolation to infinity provides an error in the estimation of the terminal slope and, therefore, an error in both the $t_{1(z)}$ and MRT.

In this paper the $t_{z(z)}$ and the MRT were determined analytically by means of curve fitting of the data with a sum of exponential terms. The MRT may be considered as the sum of weighted half times. All distribution half times and the terminal half time $\left(t_{\left.t_{(z)}\right)}\right)$ are taken into account (appendix 4).

The curve fitting mostly required five exponential terms; the number of the terms had an impact on both the $t_{t(z)}$ and the MRT. The variation in the MRT, however, was smaller than in the $t_{1(z)}$, when the number of fitted terms was changed. Both the MRT and particularly the $t_{t(2)}$ depend on the fitted mathematical model.

A sufficiently long observation period is important for an accurate estimation of the $t_{t_{(z)}}$ and MRT. The error in the MRT may strongly depend on the error in the estimated terminal $t_{1(2)}$ when the weighting factor of $t_{1(z)}$ - that is, the relative terminal area (eq 3.4)-is large. An accurate estimation of the MRT of PER requires a longer observation period than that of TRI because of the relatively large terminal area. On the other hand, TRI requires frequent sampling in the distribution phase because of the relatively large area in the distribution phase.

In the present study it was found that the total observation period must be at least 250 hours for PER whereas for TRI a period of at least 150 hours will be sufficient. The AUC, $\mathrm{Cl}_{\text {pul }}$, and $\mathrm{Cl}_{\text {hep }}$ were not sensitive to the periods of observation in this range.

For the inert PER, the intrasubject variation in the predicted cumulation is small and once the individual unit impulse response has been determined it is useful to predict the accumulation in the blood at repeated exposure. Both experiments at rest and exercise are suitable to give a representative unit impulse response. The intersubject variation in the cumulation was about twofold. The amount of fat and the level of cumulation seems to be positive correlated. For our subjects the range of the amount of fat was limited (7$22 \mathrm{~kg}$ ) and, therefore, in the industrial field the interindividual variation may be expected to be larger.

For the highly metabolised TRI the intrasubject variation in the cumulation is substantial and appears to be caused by delayed elimination during the distribution phase at the exposure under conditions of exercise. This delay of elimination was reflected in the longer MRT. Physical exercise in the range of $0-65 \mathrm{~W}$ seems hardly to affect the hepatic clearance. The intersubject variation in the predicted cumulation was about 10-fold.
To predict the individual accumulation of TRI in $\overline{\bar{z}}$ the blood in the industrial field it is likely that individual kinetics determined with exposure at exer- $-\frac{0}{2}$ cise is more suitable than at rest; for PER an: experiment at rest will suffice.

With the same level of exposure and respiratoryo intake $\left(=\mathrm{C}_{\mathrm{l}} \dot{\mathrm{V}}_{\mathrm{a}}\right)$ the intra and interindividualo variability in accumulation of TRI in the blood may bes affected by the level of physical exercise during theo workshift. In this respect, in occupational practice correction of a measured biological marker such as $\mathrm{s}^{\infty}$ blood concentrations by means of an estimated $\overrightarrow{0}$ individual minute volume of ventilation will be of little $\overrightarrow{-}$ help.

This is confirmed in occupational practice. In ano industrial exposure to toluene it was shown that the use of intake instead of exposure data to include thet effect of the pulmonary ventilation did not improve the correlation with the biological marker. ${ }^{26}$

Our predictions of the accumulation of PER and TRI are similar to those derived from experimental $\vec{\circ}$ published data and of predictions made by $a^{-}$ physiological simulation model. This suggests that short term exposures are suitable to make predictionso for repeated long term exposures on an individualo basis.

For both PER and TRI the MRT is more suited to® predict accumulation with repeated exposure than the terminal half time.

For each individual, once the kinetics have ben determined reliable predictions may be made matter the life style and the constitution of the body To estimate the individual health risks by means of ao predicted concentration time course of the toxic agento or metabolite, the theory of system dynamics based on $\varrho$ the individual unit impulse response is more $\overrightarrow{0}$ appropriate than physiological simulation models.

This study was supported by the Ministry of Sociap Affairs and Employment. I am most grateful to $\mathrm{J} F \mathrm{~J}$ Smolders for his technical help and Professor Dr R $L_{3}^{\mathbb{N}}$ Zielhuis, Professor Dr J M van Rossum, and Dr A C Monster for a critical review of the manuscript.

\section{Appendix 1}

Symbols and abbreviations used in the text and appendices 2 , 글 3 , and 4 .

$\mathrm{C}_{\text {ven }}$

Concentration of solvent in mixed venous. blood returning to the lungs (in arteria pul $\frac{N}{\sigma}$

$\mathrm{C}_{\mathrm{alv}, \mathrm{eq}} \quad$ monalis) $(\mu \mathrm{mol} / \mathrm{l})$

$\begin{array}{ll}\mathrm{C}_{\mathrm{art}} & \text { with } \mathrm{C}_{\mathrm{ven}} \text {-that is, } \mathrm{C}_{\text {ven }} / \lambda(\mu \mathrm{mol} / \mathrm{l}) \text { Concentration of solvent in arterial blood (ing }\end{array}$

veina pulmonalis) $(\mu \mathrm{mol} / 1)$

$\mathrm{C}_{\text {alv,noneq }}$ equilibrium with $\mathrm{C}(\mu \mathrm{mol} / \mathrm{l})$ 
$\mathrm{C}_{\mathrm{I}} \quad$ Concentration in inhaled air $(\mu \mathrm{mol} / \mathrm{l})$

$\dot{\mathrm{V}}_{\mathrm{a}} \quad$ Functional alveolar ventilation during exposure: virtual alveolar ventilation in equilibrium with $\mathrm{C}_{\text {ven }}(1 / \mathrm{min})$

$\dot{\mathrm{V}}_{\mathrm{a}}^{*} \quad$ Functional alveolar ventilation in the postexposure period ( $1 / \mathrm{min})$

RFI Rate of functional intake $\left(=\mathrm{C}_{1} \dot{\mathrm{V}}_{\mathrm{a}}\right)(\mu \mathrm{mol} / \mathrm{min})$

$t_{1} \quad$ Duration of exposure (min)

$t_{\text {obs }} \quad$ Total observation period (hours)

$\lambda \quad$ Blood/air partition coefficient

A1 Area under the $\mathrm{C}_{\mathrm{alv}, \infty \mathrm{a}}$ curve during exposure $(\mu \mathrm{mol} . \mathrm{min} / \mathrm{l})$

A2 Area under the $\mathrm{C}_{\mathrm{al}, \mathrm{eq}}$ curve after exposure $(\mu \mathrm{mol} . \mathrm{min} / \mathrm{l})$

AUC Area under unit impulse response in alveolar air $(\mathrm{min} / \mathrm{l})$

$\mathrm{Cl}_{\text {hep }} \quad$ Apparent hepatic clearance (appendix 3, eq 2.1) $(1 / \mathrm{min})$

$\begin{array}{ll}\mathrm{Cl}_{\text {pul }} & \text { Pulmonary clearance }\left(=\dot{\mathrm{V}}_{\mathrm{a}} / \lambda\right)(1 / \mathrm{min}) \\ \mathrm{Cl}_{\mathrm{pul}} & \text { Weighted pulmonary clearance }(\mathrm{eq} 2.8)(1 / \mathrm{min})\end{array}$

TBC, TBC* Total body clearance during and after exposure respectively (eq 2.6$)(1 / \mathrm{min})$

$\overline{\text { TBC }}$ Weighted total body clearance (eq 2.7$)(1 / \mathrm{min})$

$t_{t(z)} \quad$ Terminal half time (eq 3.5, min) (hours)

MRT Mean residence time (eqs 3.1, 3.7) (hours)

$\mathbf{V}_{\text {dss }}$

Volume of distribution at steady state $(=\mathrm{MRT} \times \mathrm{TBC})(1)$

\section{Appendix 2}

During an exposure with a constant rate of input $q_{1}$ the concentration $\mathrm{C}(\mathrm{t})$ may be written as

$$
C(t)=q_{1} \int_{0}^{t-t_{1,1}} g\left(t^{\prime}\right) d t^{\prime}
$$

where $t_{1, a}$ and $t_{1, b}$ are the starting and termination points of period of the exposure (fig 4). After exposure $C(t)$ equals:

$$
C(t)=q_{1} \int_{t-t_{1, b}}^{t-t_{1,0}} g\left(t^{\prime}\right) d t^{\prime}
$$

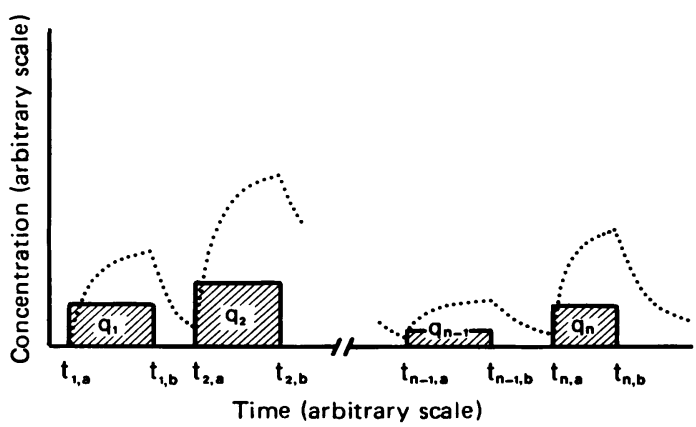

Fig 4 A schematic presentation of a number ( $n$ ) of blocks of exposure. $q_{1} \ldots q_{n}$ present the respiratory inputs (umol/min). Time course $C(t)$ may be predicted with use of impulse response.
After two exposures with $q_{1}$ and $q_{2}$ the $C(t)$ equals:

$$
C(t)=q_{1} \int_{t-t_{1, b}}^{t-t_{1,0}} g\left(t^{\prime}\right) d t^{\prime}+q_{2} \int_{t-t_{2, b}}^{t-t_{2, b}} g\left(t^{\prime}\right) d t^{\prime}
$$

In general at repeated exposures of $\mathbf{n}$ blocks with input $q_{1} \ldots q_{n}($ fig 4$)$ the $C(t)$ during the nth block equals:

$$
\begin{array}{r}
C(t)=\sum_{t_{n, a}<t<t_{n, b}}^{n-1} q_{i=1} \int_{t-t_{i, b}}^{t-t_{i, a}} g\left(t^{\prime}\right) d t^{\prime}+ \\
q_{n} \int_{0}^{t-t_{n, a}} g\left(t^{\prime}\right) d t^{\prime}
\end{array}
$$

After the nth block $\mathrm{C}(\mathrm{t})$ equals:

$$
\underset{t>t_{n, b}}{C}(t)=\sum_{i=1}^{n} q_{1} \int_{t-t_{i, b}}^{t-t_{i, a}} g\left(t^{\prime}\right) d t^{\prime}
$$

The right side of the eqs 4.4 and 4.5 consists of $n$ terms. The impact of the first terms on the actual $C(t)$ value depends on their input rates $q_{i}(i=1 \ldots n)$ and the subareas under the $g(t)$ curve. It appears clear that with increasing the actual time the impact of the first blocks is decreasing.

\section{Appendix 3}

\section{Hepatic clearance}

The apparent hepatic clearance may be calculated as:

$$
\mathrm{Cl}_{\text {hep }}=\frac{\text { total hepatic excretion }}{\int_{0}^{\infty} \mathrm{C}_{\text {art }} \mathrm{dt}}
$$

It is assumed that there is no excretion in the gut and, therefore, the hepatic blood flow has an arterial concentration $\mathrm{C}_{\mathrm{ar}}$. Total hepatic excretion may be derived from the non-exhaled fraction of the functional intake. ${ }^{10}$ In the experiments the alveolar concentration $\left(\mathrm{C}_{\mathrm{alv}, \mathrm{eq}}\right)$ in equilibrium with the concentration in mixed venous blood $\left(\mathrm{C}_{\text {ven }}\right)$ has been measured. The area under the $\mathrm{C}_{\mathrm{art}}$-curve (eq 3.1) may be deduced from the $\mathrm{C}_{\mathrm{alv}, \mathrm{eq}}\left(=\mathrm{C}_{\mathrm{ven}} / \lambda\right)$ curve.

To find the total area one has to split up this area in an exposure and a postexposure part because at $t<t_{1} C_{a r t}>C_{v e n}$ and at $\mathrm{t}>\mathrm{t}_{1} \mathrm{C}_{\mathrm{art}}<\mathrm{C}_{\mathrm{ven}}$ :

$$
\begin{aligned}
& \int_{0}^{t_{1}} C_{a r t} d t \approx 1 \cdot 2 \times \lambda \int_{0}^{t_{1}} C_{a l v, e q} d t \\
& \int_{t_{1}}^{\infty} C_{a r t} d t=\left(\lambda-\dot{V}_{a}^{*} / Q\right) \int_{t_{1}}^{\infty} C_{a l v, e q} d t
\end{aligned}
$$

At $\mathrm{t}<\mathrm{t}$, it has been assumed that the concentration in exhaled alveolar air after normal respiration is proportional to $\mathrm{C}_{\mathrm{art}}: \mathrm{C}_{\mathrm{alv}, \text { noneq }} \approx \mathrm{C}_{\mathrm{arr}}$ and $\mathrm{C}_{\mathrm{alv}, \text { noneq }} \approx 1.2 \mathrm{C}_{\mathrm{alv}, \mathrm{eq}}{ }^{9}$ At $\mathrm{t}>\mathrm{t}_{1} \mathrm{C}_{\mathrm{arr}}=(1-$ $\left.E_{p u l}\right) C_{v e n}$ with $E_{p u l}=V_{a}^{*} / \lambda Q$ with $V_{a}^{*}$ equals the postexposure 
alveolar ventilation. The area under $C_{a r t}$ (eq 2.1) equals the sum of the areas in eqs $2.2 \mathrm{a}, \mathrm{b}$.

The total body clearance (TBC) is not simply the sum of the hepatic and pulmonary clearance because the clearances are in series and not in parallel.

At steady state in the lungs the input equals the output:

$$
\mathrm{C}_{\mathrm{l}} \cdot \dot{\mathrm{V}}_{\mathrm{a}}+\mathbf{Q} \cdot \mathrm{C}_{\mathrm{ven}}=\mathbf{Q} \cdot \mathrm{C}_{\mathrm{art}}+\dot{\mathrm{V}}_{\mathrm{a}} / \lambda \cdot \mathrm{C}_{\mathrm{ven}}
$$

where $C_{1} \dot{V}_{\mathrm{a}}$ equals the respiratory input and $\dot{V}_{\mathrm{a}} / \lambda=\mathrm{Cl}_{\text {pul. }}{ }^{10}$

The $\mathrm{Cl}_{\text {hep }}$ may be written as:

$$
\mathrm{CL}_{\text {hep }}=\left(\mathrm{C}_{\mathrm{art}}-\mathrm{C}_{\text {ven }}\right) \mathrm{Q} / \mathrm{C}_{\mathrm{art}}
$$

Therefore $C_{a r t}=C_{v e n} \cdot Q /\left(Q-C l_{\text {hep }}\right)$

The $\mathrm{C}_{\mathrm{ven}}$ at steady state (SS) with use of eq 3.3 equals:

$$
\left(C_{\text {ven }}\right)_{s s}=\frac{C_{l} \dot{V}_{a}}{Q \cdot C l_{\text {hep }} /\left(Q-C_{\text {hep }}\right)+C l_{\text {pul }}}
$$

Equation 3.5 can be considered as the well known formula: $\mathrm{C}_{\text {ven(SS) }}=$ rate of infused input/total body clearance; therefore:

$$
\mathrm{TBC}=\mathbf{Q} \cdot \mathrm{Cl}_{\text {hep }} /\left(\mathbf{Q}-\mathrm{Cl}_{\text {hep }}\right)+\mathrm{Cl}_{\mathrm{pul}}
$$

In the present experiments the time course of $\mathrm{C}_{\mathrm{alv}, \mathrm{eq}}\left(=\mathrm{C}_{\mathrm{ven}} /\right.$ $\lambda$ ) is measured and, therefore, the TBC has been defined as the clearance working on the $C_{v e n}$. The total body clearance working on $\mathrm{C}_{\mathrm{ar}}$ may be obtained by multiplying the TBC (eq 3.6) with $\left(Q-\mathrm{Cl}_{\text {hep }}\right) / \mathrm{Q}$. To calculate the $\mathrm{TBC}$ the cardiac output $Q$ must be estimated. The term $Q \cdot C l_{\text {hep }} /\left(Q-C_{\text {hep }}\right)$ (eq 3.6) is not sensitive to changes in $Q$. At $\mathrm{Cl}_{\text {hep }}=0.5 \mathrm{l} / \mathrm{min}$ and at $\mathrm{Cl}_{\text {hep }}=1.71 / \mathrm{min}$ the term is $0.538-0.555$ and $2.245-2.575$ respectively when $Q$ changes from 7 to $51 / \mathrm{min}$.

At the experiments with exercise during exposure both the alveolar ventilation $\left(\dot{V}_{\mathrm{g}}\right)$ and the cardiac output $(Q)$ will exceed the postexposure ventilation $\left(\dot{\mathrm{V}}_{\mathrm{a}}{ }^{*}\right)$ and cardiac output.

For the exercise experiments a total body clearance during (TBC) and after exposure (TBC*) were calculated with the cardiac output estimated as $10 \mathrm{l} / \mathrm{min}$ and $6.5 \mathrm{l} / \mathrm{min}$ respectively (eq 3.6). The weighted TBC equals:

$$
\overline{\mathrm{TBC}}=\left(\mathrm{A} 1 \cdot \mathrm{TBC}+\mathrm{A} 2 \cdot \mathrm{TBC}^{*}\right) /(\mathrm{A} 1+\mathrm{A} 2)
$$

The weighted pulmonary clearance equals:

$$
\overline{\mathrm{Cl}}_{\mathrm{pul}}=\left(\mathrm{A} 1 \cdot \dot{\mathrm{V}}_{\mathrm{a}} / \lambda+\mathrm{A} 2 \dot{\mathrm{V}}_{\mathrm{a}}^{*} / \lambda\right) /(\mathrm{A} 1+\mathrm{A} 2)
$$

$A 1$ and $A 2$ are the areas under the $C_{\text {alveq }}$ curve during and after exposure respectively.

\section{Appendix 4}

Mean residence time
The MRT may be defined in terms of eliminated amounts:

$$
\text { MRT }=\sum_{i=1} A_{i} \cdot t_{i} / A_{\text {tot }}
$$

where $A_{i}$ is the amount leaving the body at time $t_{i} ; A_{i}$ has residence time $t_{i} . A_{\text {tot }}$ is the total eliminated amount ando equals the dose. The amount leaving the body between times $t_{i}$ and $t_{i}+d t$ is $d A$ and

$$
\text { MRT }=\int_{0}^{A_{\text {tot }}} \mathrm{tdA} / \mathbf{A}_{\mathrm{tot}}
$$

The amount $\mathrm{dA}$ can be set equal to TBC.Cdt:

$$
\text { MRT }=\int_{0}^{\infty} \text { TBC.C.tdt } / \int_{0}^{\infty} \text { TBC.C dt }
$$

where $\mathrm{C}$ is the concentration in the blood and $\mathrm{TBC}$ is the total body clearance.

Assuming a constant TBC the MRT can be defined $\mathrm{as}^{2}$ :

$$
\text { MRT }=\int_{0}^{\infty} \mathrm{t} . \mathrm{Cdt} / \int_{0}^{\infty} \mathrm{Cdt}
$$

The concentration in blood $\mathrm{C}(\mathrm{t})$ may be presented by the exhaled alveolar concentration $\mathrm{C}_{\text {alv,eq }}$. During and afte exposure with duration $t_{1}$, the $C_{\text {alv,eq }}$ may be written as:

$$
\begin{gathered}
C_{\substack{a l v, e q \\
t \leqslant t_{1}}}=\sum_{i=1}^{p} c(i)\left(1-e^{r(i) t}\right) \\
\underset{\substack{a l v, e q \\
t \geqslant t_{1}}}{C_{i=1}}=\sum_{i=1}^{p} c(i)\left(e^{r(i)\left(t-t_{1}\right)}-e^{r(i) t}\right)
\end{gathered}
$$

with $\mathbf{r}(\mathbf{i})=$ negative.

Assuming a constant TBC the MRT may be calculateक according to eq 3.1 :

$$
\text { MRT }=\frac{1}{2} \mathrm{t}_{1}-\sum_{\mathrm{i}=1}^{\mathrm{p}}(\mathrm{c}(\mathrm{i}) / \mathrm{r}(\mathrm{i})) / \sum \mathrm{c}(\mathrm{i})
$$

The MRT (eq 3.3) may be written as the sum of weighted half times:

$$
\text { MRT }=\frac{1}{2} t_{1}+1 \cdot 44 \sum_{i=1}^{p}\left(c(i) / \sum c(i)\right) \cdot t_{\frac{1}{2}(i)}
$$

with

$$
t_{t(i)}=-0 \cdot 693 / r(i)
$$

All half times are weighted with c(i)/ $\Sigma c(i)$. When the concen tration-time profile may be adequately fitted with only one? exponential term the $M R T P \simeq 1 \cdot 44 . t_{t(z)}$; all amounts of the solvent are distributed and eliminated during the termina/ phase. When two or more exponential terms are required the $e^{\omega}$ MRT $<1.44 t_{t(z)} ;$ a part has been already eliminated during $\sigma$ the distribution phase.

The unit impulse response $\mathrm{g}(\mathrm{t})$ derived from eqs $4.2 \mathrm{a}, \mathrm{b}$ and the rate of respiratory input $\mathrm{RFI}^{10}$ equals: 


$$
g(t)=(-1 / R F I) \sum c(i) r(i) e^{r(i) t}
$$

with

$$
A U C=\sum c(i) / R F I
$$

The area corresponding to an exponent $r(i)$ relative to AUC is $\mathrm{c}(\mathrm{i}) / \Sigma \mathrm{c}(\mathrm{i})$.

The kinetic response after an impulse response-for example, a bolus injection-equals $C(t)=D \cdot g(t)$ and when a constant TBC is assumed the same MRT according to eq 4.3 with $t_{1}=0$ is yielded.

In the present experiments at exercise the TBC (eq 3.6) is not a constant because the $\mathrm{Cl}_{\text {pul }}\left(=\hat{\mathrm{V}}_{\mathrm{a}} / \lambda\right)$ during exposure exceeds the post exposure $\mathrm{Cl}_{\mathrm{pul}}\left(=\mathrm{V}_{\mathrm{a}}^{*} / \lambda\right)$. Hence

MRT $=\left(\operatorname{TBC} \int_{0}^{t_{1}} t \cdot C d t+T_{B C}^{*} \int_{t_{1}}^{\infty} t \cdot C d t\right) / d o s e$

where the TBC and $\mathrm{TBC}^{*}$ are the time weighted total body clearance during and after exposure; the dose equals the total respiratory input (is the total functional intake $\hat{V}_{\mathbf{2}} \cdot C_{\mathbf{l}} \cdot t_{1}$ ).

According to eq 4.7:

$$
\begin{aligned}
\text { MRT }= & (1 / \text { dose })\left[\lambda T B C \sum \frac{1}{2} \mathrm{c}(\mathrm{i}) \mathrm{t}_{1}^{2}-\lambda \mathrm{TBC}^{*} \sum \mathrm{c}(\mathrm{i}) \mathrm{t}_{1} / \mathrm{r}(\mathrm{i})-\right. \\
& \lambda\left(\mathrm{TBC}-\mathrm{TBC}^{*}\right) \\
& \left.\sum\left(\mathrm{c}(\mathrm{i})\left(1-\mathrm{e}^{\mathrm{r}(\mathrm{i}) \mathrm{t}_{1}}\right) / \mathrm{r}(\mathrm{i})^{2}+\mathrm{c}(\mathrm{i}) \mathrm{t}_{1} \mathrm{e}^{\mathrm{r}(\mathrm{i}) \mathrm{t}_{1}} / \mathrm{r}(\mathrm{i})\right)\right]
\end{aligned}
$$

For PER the term $\lambda$ (TBC-TBC*) equals $\dot{\mathrm{V}}_{-}-\dot{\mathrm{V}}_{a}{ }^{*}$ whereas for TRI the TBC has been estimated with a cardiac output of 6.5 $1 /$ min (eq 3.6). When TBC $=T_{B C}^{*}$ eq 4.8 equals eq 4.3. For the sake of simplicity in eq 4.8 during and after exposure the c(i), r(i) are set equal.

The MRT can also be determined with the total amount $A_{b}(t)$ of the agent in the body as function of time $e^{27}$ :

$$
\operatorname{MRT}=\int_{0}^{\infty} A_{b}(t) d t / d o s e
$$

It may be verified that the MRT according to eq 4.9 gives the same result as eq 4.3 with $t_{1}=0$.

In general the amount of the agent in the body as function of time is difficult to measure when various routes of elimination occur. Therefore, to determine the MRT frequent measurement of the cumulative metabolic excretion in urine may be helpful.

\section{References}

1 Wagner JG. Scientific commentary. Do you need a pharmacokinetic model, and, if so, which one? J Pharm Biopharm 1975;3: 457-78.

2 Cutler DJ. Theory of the mean absorption time, and adjunct to conventional bioavailability studies. J Pharm Pharmacol 1978; 30:476-8.

3 Yamaoka K, Nakagawa T, Uno T. Statistical moments in pharmacokinetics. J Pharmacokinet Biopharm 1978;6:547-58.
4 Weiss M, Förster W. Pharmacokinetic model based on circulatory transport. Eur J Clin Pharmacol 1979;16:287-93.

5 Riegelman S, Collier P. Scientific commentary. The application of statistical moment theory to the evaluation of in vivo dissolution time and absorption time. J Pharmacokinet Biopharm 1980;8:509-34.

6 Rossum JM van, Burgers J, Lingen G van, Bie J de. Pharmacokinetics: a dynamic system approach. TIPS 1983;4:27-30.

7 Brockmeier D. Model-free evaluation and mean-time concept in pharmacokinetics. Methods Find Exp Clin Pharmacol 1986; 8:593-602.

8 Fernandez JG, Droz PO, Humbert BE, Caparos JR. Trichloroethylene exposure. Simulation of uptake, excretion, and metabolism using a mathematical model. Br J Ind Med 1977; 34:43-55.

9 Opdam JJG, Smolders JFJ. Alveolar sampling and fast kinetics of tetrachloroethene in man. I. Alveolar sampling. $\mathrm{Br} \mathrm{J}$ Ind $\mathrm{Med}$ 1986;43:814-24.

10 Opdam JJG. Respiratory input in inhalation experiments. $\mathrm{Br} J$ Ind Med 1989;46:145-56.

11 Opdam JJG, Smolders JFJ. A method for the retrospective estimation of the individual respiratory intake of a poorly and highly metabolising solvent during rest and physical exercise. Br J Ind Med 1989;46:250-60.

12 Durmin IVGA, Wormersley J. Body fat assessed from total body density and its estimation from skinfold thickness. Br J Nutr 1974;32:77-83.

13 Veng-Pedersen $P$. Novel deconvolution method for linear pharmacokinetic systems with polyexponential impulse response. J Pharm Sci 1980;3:312-8.

14 Vaughan DP, Dennis M. Mathematical basis of the point-area deconvolution method for determining the vivo input functions. J Pharm Sci 1978;67:663-7.

15 Benet LZ. Noncompartmental determination of the steady state volume of distribution. J Pharm Sci 1979;68:1071-4.

16 Akaike H. A Bayesian extension of the minimum AIC procedure of autoregressive model fitting. Biometrika 1979;66:237-42.

17 Boxenbaum HG, Riegelman S, Elashoff RM. Statistical estimations in pharmacokinetics. J Pharmacokinet Biopharm 1974;2: 123-48.

18 Stewart RD, Baretta ED, Dodd HC, Torkelson TR. Experimental human exposure to tetrachloroethylene. Arch Environ Health 1970;20:224-9.

19 Monster A, Regouin-Peeters W, Schijndel A van, Tuin J van der. Biological monitoring of occupational exposure to tetrachloroethene. Scand J Work Environ Health 1983;9:273-81.

20 Stewart RD, Dodd HC, Gay HH, Erley DS. Experimental human exposure to trichloroethene. Arch Environ Health 1970;29: 64-71.

21 Droz PO, Fernandez JG. Effect of workload on retention and metabolism of inhaled organic solvents. A comparative theoretical approach and its applications with regards to exposure monitoring. Int Arch Occup Environ Health 1977; 38:231-46.

22 Fiserova-Bergerova V. Modeling of metabolism and excretion in vivo. In: Fiserova-Bergerova V, ed. Modeling of inhalation exposure to vapors: uptake, distribution and elimination. Vol I. Boca Raton: CRC Press, 1983:101-32.

23 Sato A, Nakajima T, Fujiwara Y, Murayama N. A pharmacokinetic model to study the excretion of trichloroethylene and its metabolites after an inhalation exposure. $\mathrm{Br} \mathrm{J}$ Ind Med 1977; 34:56-63.

24 Wilkinson GR, Shand DG. A physiological approach to hepatic drug clearance. Clin Pharmacol Ther 1975;18:377-90.

25 Engström J, Riihimäki V. Distribution of m-xylene to subcutaneous adipose tissue in short-term experimental human exposure. Scand J Work Environ Health 1979;5:126-34.

26 Droz PO, Berode M, Boillat MA, Lob M. Biological monitoring and health surveillance of rotagravure printing workers exposed to toluene. In: Dillon K, Ho MH, eds. Biological monitoring of exposure to chemicals (organic compounds). New York: John Wiley, 1987:113-31.

27 Veng-Pedersen P, Gillespie W. Mean residence time in peripheral tissue: a linear disposition parameter useful for evaluating a drug's tissue distribution. J Pharmacokinet Biopharm 1984; 12:535-43. 